\title{
ABNORMALITIES IN AUDITORY EVOKED POTENTIALS OF 75 PATIENTS WITH ARNOLD-CHIARI MALFORMATIONS TYPES I AND II
}

\author{
Paulo Sergio A. Henriques Filho', Riccardo Pratesi²
}

\begin{abstract}
Objective: To evaluate the frequency and degree of severity of abnormalities in the auditory pathways in patients with Chiari malformations type I and II. Method: This is a series-of-case descriptive study in which the possible presence of auditory pathways abnormalities in 75 patients (48 children and 27 adults) with Chiari malformation types I and II were analyzed by means of auditory evoked potentials evaluation. The analysis was based on the determination of intervals among potentials peak values, absolute latency and amplitude ratio among potentials V and I. Results: Among the 75 patients studied, 27 (36\%) disclosed Arnold-Chiari malformations type I and 48 (64\%) showed Arnold-Chiari malformations type II. Fifty-thre $(71 \%)$ of these patients showed some degree of auditory evoked potential abnormalities. Tests we renormal in the remaining $22(29 \%)$ patients. Conclusion: Au ditoryevoked potentials testing can be considered a valuable instrument for diagnosis and evaluation of brain stem functional abnormalities in patients with Arnold-Chiari malformations type I and II. The determination of the presence and degree of severity of these abnormalities can be contributory to the prevention of further handicaps in these patients either through physical therapy or by means of precocious corrective surgical intervention.
\end{abstract}

KEY WORDS: Arnold-Chiari malformations type I and type II, auditory evoked potentials.

\begin{abstract}
Anormalidades nos potenciais evocados auditivos de 75 pacientes com os tipos I e II das malformações de Arnold-Chiari
\end{abstract}

RESUMO - Objetivo: Avaliar a freqüência e grau de comprometimento das vias auditivas em tronco cerebral por meio de potencial evocado auditivo, em pacientes afetados por malformações de Amold-Chiari de tipos I e II. Método: Foi efetuado um estudo descritivo de tipo série de casos, sendo selecionados 75 pacientes (48 crianças e 27 adultos) nos quais foi realizada avaliação dos potenciais evocados das vias auditivas, com base à determinação dos valores dos intervalos entre picos de potenciais, da latência absoluta e da razão entre as amplitudes dos potenciais V e I. Resultados: En tre os 75 pacientes avaliados, 27 (36\%) a p resentavam malformações de Arnold-Chiari de tipo I e 48 (64\%) apresentavam malformações de tipo II. Em $53(71 \%)$ do total de pacientes os potenciais evocados auditivos mostraram algum grau de anormalidade. Os testes foram normais nos restantes $22(29 \%)$. Conclusão: O potencial evocado auditivo pode ser considerado valioso instrumento para o diagnóstico e avaliação da gravidade das anormalidades funcionais de tronco cerebral em pacientes port a d o resde malformações de Arnold-Chiari de tipo I e II. Esta avaliação pode contribuir de maneira significativa não somente no diagnóstico como também na prevenção de ulterio res lesões, pela adoção de medidas preventivas, tanto por meio de fisioterapia como por intervenção cirúrgica precoce.

PALAVRAS-CHAVE: malformação de Arnold-Chiari de tipo I e de tipo II, potenciais evocados auditivos.

Neural tube defects affect 3 children out of 1000 bornalive 1 . Among these anomalies are the malformations described by Chiari in 1891 and almost concurrently by Arnold, two pioneers in the study of such defects in human beings ${ }^{2}$. There are four types of Chiari malformations: type I is identified by herniation of cerebellar tonsils and medulla oblongata, through the foramen magnum. Type II is character- ized by elongation and caudal displacement of the ce rebellar vermis, associated with herniation of cerebellar tonsils, lower brain stem and forth ventricle. In addition medullary kinking, midbrain deformities and aqueductal stenosis can also be seen. Spinal dysraphism occurs in about $90 \%$ of these patients and one out of five develops signs and symptoms of brain stem dysfunction. Chiari type III is the rarest of the

${ }^{1} \mathrm{~N}$ e u rophysiology Department, MD, International Center of Neural Science and Rehabilitation, North Lake SARAH Hospital, Brasilia DF, Brazil; ${ }^{2} \mathrm{MD}$, PhD, University of Brasilia School of Medicine Pos-Graduation Program, Brasilia DF, Brazil. Senior Fellow Researcher.

Received 12 September 2005, received in final form 23 January 2006. Accepted 5 April 2006.

Dr. Paulo Sérgio Azeredo Henriques Filho - SMLN Trecho 06 - Chácara 232 / casa 02 - 71540-060 Brasília DF - Brasil. E-mail: pazeredo@ linkexpress.com.br 
Chiari malformations and is generally associated with a somber prognosis in terms of severe disability and early death. Anatomically is characterized by the association of high cervical or occipital encephalocele and the presence of many of the abnormalities usually found in the second type. Finally the type IV, that is the less complex of Chiari malformations, is solely expressed by a variable degree of cerebellar hypoplasia. Although patients with Arnold-Chiari I malformation are generally asymptomatic at birth, they may eventually develop prog ressive brain stem dysfunction during their lives. This dysfunction can be produced by traumatic, vascular or inflammatory episodes or by any other kind of damaging events. Patients with type II Arnold-Chiari malformation are generally symptomatic since birth but the above mentioned deleterious episodes can aggravate their pre-existing condition ${ }^{3,4}$. Due to their position in the brain stem the auditory pathways are frequently injured. In Arnold-Chiari malformations these injuries may include all segments of the auditory system such as the distal and proximal regions of the cochlear nerve, and the auditory pathways running through the superior region of the bulb, the superior and inferior region of the pons, and the inferior region of the mesencephalon ${ }^{5}$.

There is an evident diffe rence in the period of life during which patients with Arnold-Chiari malformations I or II will look for medical assistance. Due to the benignity of their clinical picture patients with type I will eventually appear at rehabilitation centers during their adult life. That is not the case of patients with type II malformations that, in general, are $b$ rought to medical attention during the first years of their life due to the precocity and severity of their symptoms mainly characterized by an early functional limitation of movements and the almost constant p resence of myelomeningocele with the consequent urinary bladder disorder. This is the most probable explanation for the diffe rence in the number of patients with type I and II Arnold-Chiari malformations found in our study. The analysis of brain stem auditory-evoked potentials is frequently utilized to detect abnormalities in the auditory pathways and several authors have applied this method in the evaluation of patients with Arnold-Chiari malformations type II. On the other hand, auditory-evoked potentials studies focusing on the abnormalities of the auditory pathways of patients with Arnold-Chiari malform ation type I are rare.

Studies focusing on the abnormalities in the auditory pathways of patients with Arnold-Chiari malformations are scanty in the literature, this fact being p a rticularly true in the case of Arnold-Chiari malformation type I. Trying to contribute to a more detailed knowledge on brain stem functioning of these patients, the aim of the present study was to evaluate the frequency and degree of severity of the abnormalities in the auditory pathways in patients with Arnold-Chiari malformations type I and II. A more detailed knowledge of the characteristics of their $a b$ n ormalities and of their future evolution could be contributory to the management of these patients, trying to prevent further handicaps, both through physical therapy or by means of a precocious corre ctive surgical intervention.

\section{METHOD}

This is a series-of-case descriptive study, carried out after the approval of the Ethic Committee of the SARAH Rehabilitation Hospitals Network as well as the approval of the re Iatives and/or the patients involved in the study. The sample size, of this study was composed by 75 subjects with Arnold-Chiari malformation. The data were collected and analyzed between march 2002 and march 2003. Individuals without Arnold-Chiari malformation were excluded from the selection after interviews and clinical or radiological examinations, as well as patients with encephalic injuries, ne uropathies or those using medications such as, for example aminoglycosides, in order to avoid any undue interference in the analysis of the data. All patients underwent auditoryevoked potentials test during the morning and in waking state.

The data were collected with a Medtronic instrument and Key-point software (Medtronic Functional Diagnostics A/S, Denmark) and utilizing a Key-point software (Version 3.0, of the Medtronic Functional Diagnostics A/S). Auditory potentials were recorded through gold recording electrodes which were attached to the skin with collodion, and filled with conductive jelly. The electrodes were placed on $\mathrm{Cz}$ scalp position and on the left and right mastoid process. The register of the auditory potentials was obtained utilizing the three following channels: the $\mathrm{M} 1-\mathrm{Cz}$ (M for mastoid process), the M2-CZ and the M1-M2. Were used two limiting filters, one inferior to $2 \mathrm{~Hz}$ and one superior to 3 $\mathrm{KHz}$. The frequency of the stimulus was equal to $11 \mathrm{~Hz}$ and its intensity was of $100 \mathrm{~dB}$. The stimulus modality was the $r$ a refaction click, with mask of the oposite side. To evoke the potentials headphones were placed over both the patient's ears. The guidelines of the International Federation of Clinical Neurophysiology ${ }^{6}$ were strictly applyied in the evaluation of the auditory evoked potentials. The absolute latency, the latency among peaks and the amplitude ratio among potentials $\mathrm{V}$ and I were analyzed ${ }^{6}$.

The software SPSS for Windows software, (standard version, \# 10.0.1, SPSS Inc. 1999) ${ }^{7}$ was used in the statistical analysis, being evaluated the frequency of discrete and continuous variables. The median value of the central tendency was calculated in the analysis of continuous variables.

\section{RESULTS}

A total of 75 patients ( 48 children and adolescent, 
Table 1. Absolute latency central tendency, interpeak latency and amplitude ratio between the potentials $V$ and I.

\begin{tabular}{lccccccc}
\hline & \multicolumn{3}{c}{ Absolute latency central tendency } & \multicolumn{3}{c}{ Interpeak potential latency values } & Potentials V/I \\
\cline { 2 - 8 } $\begin{array}{l}\text { Types of Chiari } \\
\text { malformations }\end{array}$ & $\mathrm{I}$ & $\mathrm{III}$ & $\mathrm{V}$ & $\mathrm{I}-\mathrm{III}$ & $\mathrm{III}-\mathrm{V}$ & $\mathrm{I}-\mathrm{V}$ & $\mathrm{V} / \mathrm{I}$ \\
\hline Type I & $1.50 \pm 0.12$ & $3.70 \pm 0.32$ & $5.6 \pm 0.35$ & $2.20 \pm 0.28$ & $2.00 \pm 0.27$ & $4.15 \pm 0.30$ & $2.0 \pm 4.32$ \\
Type II & $1.50 \pm 0.14$ & $4.0 \pm 0.31$ & $6.0 \pm 0.35$ & $2.50 \pm 0.32$ & $2.05 \pm 0.26$ & $4.50 \pm 0.32$ & $1.37 \pm 0.75$ \\
\hline
\end{tabular}

I, III, V: potentials generated by components of the auditory pathways; I-III, III-V and I-V: interpeak latency (ms); potentials V/l: amplitude ratio between the potentials I and $V(\mu \mathrm{V})$.

Table 2. Number of abnormal tests, distributed according to the type of Chiari malformation and auditory pathway affect ed segment.

\begin{tabular}{lccc}
\hline Affected segment & Chiari type I & Chiari type II & Total \\
\hline Segment 1 & 30 & 19 & 49 \\
Segment 2 & 10 & 35 & 45 \\
Segment 3 & 3 & 14 & 17 \\
Without & & & \\
abnormalities & 11 & 28 & 39 \\
Total & 54 & 96 & 150
\end{tabular}

Tests: comprehend the sum of right and left auditory evoked potentials; Segment 1: part of the cochlear nerve near the cochlea (deficit defined by the absolute latency prolongation or by the absence of the potential I); Segment 2: include the segment localized between the cochlear nerve near the cochlea and the transition part of the bulb and the pons (deficit defined by the absolute latency prolongation of the potential III, and or by the interpeak latency I-III prolongation, and or by the absence of the potential III; Segment 3: part localized between the lower and upper portion of the pons (deficit defined by the absolute latency prolongation of the potential $\mathrm{V}$, and or by the interpeak latency I-V and III-V prolongation, and or by the absence of the potential V).

aged 2 to 16 , mean age 7 , and 27 adults, aged 19 to 70, mean age 38) were analyzed, 27 disclosing type I and 48 showing type II Chiari malformations. Among the patients with the type II $47(98 \%)$ were childre $n$ and adolescent, and among the type I 25 (92\%) were adult. Fifty-five $(71 \%)$ of these patients showed some degree of auditory evoked potential abnormalities. Tests were normal in the remaining 20 (27\%) patients. Among these 55 patients that showed abnormal auditory evoked potentials 21 (38.2\%) pertained to patients with Chiari type I malformation and 34 (61.8\%) to patients with type II malformation.

In Table 1, can be seen detailed data concerning the potentials values in relation with the two different types of Chiari malformation.

In Table 2 can be seen the number of abnormal tests and the corresponding affected segment of the auditory pathway.

In Graphic 1 the diff e rent abnormalities found in the auditory pathways can be visualized as: abnormal amplitude ratio between potentials $\mathrm{V}$ and $\mathrm{I}$; $\mathrm{ab}$ solute latency prolongation; interpeak latency I-III, I-V, III-V; and absence of potential I, III or V.

\section{Abnormalities in the auditory evoked potentials}

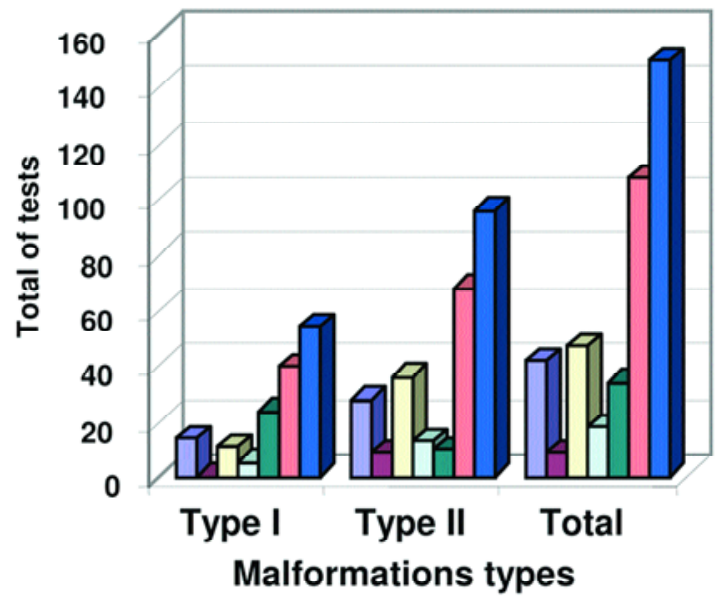

\begin{tabular}{l} 
№rmal \\
Absolute latency prolongation \\
$\square$ Interpeak latency prolongation \\
$\square$ Potentials absence \\
$\square$ Abnormal V/l amplitude ratio \\
$\square$ Total of abnormalities \\
$\square$ Total of tests \\
\hline
\end{tabular}

Graphic 1. Abnormalities found in the auditory pathway. Abso lute Latency: II, III or V absolute latency prolongation; Interpeak prolongation: I-III, III-V and or I-V interpeak prolongation, or shortening of interpeak latency I-V; Absence of potentials: $a b$ sence of potentials I, III and or V; Abnormal VII amplitude ratio: VII amplitude ratio above $1.3 \mu \mathrm{V}$ or below $0.5 \mu \mathrm{V}$; Total of abnomalities: abnormalities in the auditory evoked potentials detected from all the criteria described above.

\section{DISCUSSION}

The absence of patients with Chiari malformations type III and IV in our study can be explained by the diffe rence in structural abnormalities and in clinical manifestations that are characteristic of each type of malformation. The severity and complexity of the malformations found in type III is generally incompatible with an extended life span. On the other hand, the usual benignity of the abnormalities and the lack of serious clinical manifestations found in patients 
with type IV malformation drastically decrease their presence in hospital settings. These characteristic clinical patterns are probably the cause of the absence of patients with malformations type III and IV in our study. In this study was observed a predominance (98\%) of children and adolescent among the patient with the type II, and predominance (92\%) of adults among patients with the type $\mathrm{I}$. This discrepancy is explained by the greater complexity of the malformation type II, that due to its more severe clinical reperaussion will need an earlier medical attention ${ }^{8}$.

In the study of auditory evoked potentials abnormalities we choose to proceed with a segmental analysis of the auditory pathways since discrete groups of neurons, as generators of specific potentials, as is the case of potentials III and V, are still undetermin$\mathrm{ed}^{5,6,9,10}$. Analysis of the absolute latency values in patients with Chiari malformation type II disclosed a tendency to increased median value of potentials III and $\mathrm{V}$ when compared to normal values (Table 1). The most plausible explanation for this discre pancy is that it is probably due to the association of type II brainstem abnormalities and the sensory-neural maturation delay typically found in this kind of malformation ${ }^{5,11,12}$.

The amplitude ratio between potentials $V$ and I showed a higher median value in patients with malformation type I (Table 1). This alteration is suggestive of higher frequency of peripheral injuries of the auditory pathways, namely, sensory neural deafness and or loss of higher frequency components of these pathways. These disorders can appear alone or can be seen in association with other abnormalities. An higher frequency of these peripheral disorders of auditory pathways in patients with type I malformation can be explained by the timing in which the patients have been evaluated and by the natural history of the malformation that, during the adult life, tend to manifest functional repercussions consequent to eventual vascular or traumatic events, leading to stre tching of the cochlear nerve distally to the brain stem.

The involvement of the components responsible for higher frequencies transmission could be explained by the possible alteration of the cere b rospinal fluid circulation consequent to brain stem compression by herniated cerebellar tonsils at the foramen magnum level, with repercussion on endolymphatic fluid dynamic and resultant hydrops and cochlear nerve dysfunction.

In 68 of the 96 tests performed on patients with type II malformation (Table 2), the abnormality observed was a conduction deficit in the caudal seg- ment of the cochlear nerve. In the present study this segment has been the most frequently affected portion of the auditory pathways, a result that differ from the study of Nishimura et al. ${ }^{5}$ that reported as the most affected region the one localized between the segments of the pons. This difference is easily explained by differences in age-group of the two studies since the sample of the former authors included patients with type II Arnold-Chiari malformations, during the first year of their lives. It is known that this age-group is more prone to alterations of this portion of pons. These abnormalities, when occurring during the first year of life, result in an increased probability of brain stem dysfunction. In addition, a $p$ rolonged time of maturation of the auditory pathways may occur in children with Arnold-Chiari malformation. The auditory pathways of these childre $n$ only reach their normal latency values around 8 to 9 years of age whereas subjects without this malformation reach normal latency values around their fourt year of life ${ }^{5,11}$. These facts could explain the smaller frequency of these alterations in older patients.

Another possible explanation for the difference in findings between the two studies can be due to the methodology applied on the present study since all tests showing isolated prolongations of the interpeak latency III-V were disregarded, being conside red abnormal only when present the association of an abnormal relation of amplitude $\mathrm{V} / \mathrm{I}$ and or the lengthening of the latency between peak I-V. In Nishimura et al. ${ }^{5}$ study prolongation of the isolated interpeak latency III-V was adopted as the parameter of abnormality.

Among the 150 tests performed were detected 17 alterations due to conduction deficit between the caudal segment and the rostral segment of the pons (Table 2). This abnormality was identified by the prolongation of the latency between peaks III-V in association with a prolongation of the latency between peaks I-V and or an abnormal amplitude ratio V/I, smaller then 0.5 microvolts or yet, by the absence of the potential V. In two cases was observed a conduction deficit of the above mentioned segment, which was identified by the abnormal amplitude ratio. This fact is not described in previous articles about AmoldChiari malformations and auditory pathways conduction deficits ${ }^{5,11,13}$. It is relevant to point out that the representation of conduction deficit between the caudal segment and the rostral segment of the pons is not always related to MRI image distortions, because usually it occurs due to the dysgenesis of the brain stem of the related segment, being distinct from alte- 
rations in the medulla oblongata, whose more frequently reported alterations are secondary to trauma during life, which can be easily visualized in MRI ${ }^{14}$.

The majority of cases among the 17 cases of conduction deficits identified by the above described criteria, are represented by patients with Amold-Chiari malformation type II. This fact reinforce the statements that alterations at this level, or more precise$l y$, at the level of the pons segment of the brain stem, are alterations consequent to dysgenesis, being more complex in patients with malformations type II when compared to patients with type I malformations ${ }^{2,3}$. Analyzing the added results of all variables (Table 2 and Graphic 1) that pointed to a conduction deficits of the auditory pathways, according to the levels or segments of those pathways, a higher frequency of alterations at the peripheral level in patients with malformation type I can be noted. In patients with malformation type II, the higher frequency of alterations was registered above the cochlear nerve and below or at the level of the caudal segment of the pons. These alterations reinforce the data previously discussed about the complexity of these malformations. In the type I the cochlear nerve is the most frequently structure affected by traumatic injury during the life, whereas in type II the medulla oblongata and pons are the preferred targets.

Comparing the short latency evoked potentials alterations of the auditory pathways between malformations type I and II, a small difference in percentage was registered in the results, that is, $69 \%$ of type I patients and $63 \%$ of type II patients presented such abno malities. This slight diffe rence between the frequency of alterations in type I and II malformations could be explained by the evaluation of the several segments of the pathway, in general evaluated at different moments of the natural history of their malformations, when the research is held at the hospital level. The patients with type I generally seek rehabilitation centers assistance when there is some functional abnormality on the structureof their nerv ous system, something that generally occurs during their adult life, when they discover the syndrome. Now, patients with type II malformation, due to their precocious functional limitation of their movements, and due to the presence of urinary bladder disorders related to the almost constant presence of myelomeningocele are generally seen earliers at the rehabilitations centers, almost always during their infancy or childhood. This can explain the reason for the majority of patients in this study being children.

In conclusion, the analysis of short latency auditory evoked potentials perf o rmed in the present study, contributed to the demonstration of several degrees of brain stem abnormalities among patients with type I and II Chiari malformations. The frequency of these abnormalities, in both types of Chiari malformation was not very large. The increased frequency of abnormal findings, among the patients with type II malformation was probably related to the complexity of this type of malformation.

The analysis of the amplitude ratio between the potentials $\mathrm{V}$ and $\mathrm{I}$, in addition with the other criteria that define abnomality, allows the identification of a greater number of alterations in the auditory pathways functions of patients with Arnold-Chiari malformations types I and is a valuable tool to increase the quality and precision of the diagnosis.

Acknowledgment - The authors thank the authorization of this research at the SARAH Rehabilitation Hospitals Network. To doctors: Aloysio Campos da Paz, MD PHD President of this Network, José Carlos Dias Ferreira, MD PHD Chief of the Neurophysiology Service, Eliana Valverde Magro Borigatto, MD PHD Chief of the Pediatric Service and Régis Tavares, MD Chief of the Neurosurgical Service.

\section{REFERENCES}

1. Trimble BK, Baird PA. Congenital anomalies of the central nervous system: incidence in British Columbia, 1952-72. Teratology 1978;17:43-50.

2. Koehler PJ. Historical vignette. Chiari's description of cerebelar ectopy (1891), with a summary of Cleland's and Arnold's contributions and some early observations on neural-tube defects. J Neurosurg 1991;75: 823-826.

3. Gilbert JN, Jones KL, Rorke LB, Chernoff GF, James HE. Central nervous system anomalies associated with meningomyelocele, hydrocephalus, and the Arnold-Chiari malformation. Reappraisal of theories regarding the pathogenesis of posterior neural tube closure defects. Neurosurgery 1986;18:559-564.

4. Dyste GN, Menezes AH. Presentation and management of pediatric Chiari malformation without myelodysplasia. Neurosurgery 1988;23: 589-597.

5. Nishimura T, Mori K, Uchida Y, Ohira T, Tamura K. Brain stem auditory-evoked potentials in meningomyelocele: natural history of Chiari II malformations. Child's Nerv Syst 1991;7:316-326.

6. Pratt H, Aminoff M, Nuwer MR, Starr A. Short-latency auditory evoked potentials. In Deuschl G, Eisen A (eds). Recommendations for the practice of clinical neurophysiology: guidelines of the International Federation of Clinical Neurophysiology. $2^{\text {nd }}$ ed. Electroencephalogr Clin Neurophysiol 1999;52(Suppl):69-77.

7. SPSS for Windows. Standard version. Release 10.0.1. SPSS Inc.1999.

8. Carmel PW, Markesbery WR. Early description of theArnold-Chiari malformation: the contribution of John Cleland. Neurosu rgery 1972; 37:543-547.

9. Nuwer MR, Aminoff M, Goodin D, et al. IFCN recommended stan$\mathrm{d}$ a rds for brain-stem auditory evoked potentials: report of an IFCN committee. Electroencephalogr Clin Neurophysiol 1994;91:12-17.

10. Chiappa KH, Hill RA. Brain stem auditory evoked potentials: interpretation. In Chiappa KH (ed). Evoked potentials in clinical medicine. $3^{\text {rd }}$ ed. Philadelphia: Lippincott-Raven, 1997:199-268.

11. Fujii M, Tomita T, McLone DG, Grant JA, Stack CV, Mori K. Developmental normo-maturation of brainstem auditory evoked potentials in children with asymptomatic meningo-myelocele during the first year of life. Child's Nerv Syst 1997;13:147-153.

12. Sperling NM, Franco RA Jr, Milhorat TH. Otologic manifestations of Chiari I malformation. Otol Neurotol 2001;22:678-681.

13. Barnet AB, Weiss IP, Shaer C. Evoked potentials in infant brainstem syndrome associated with Arnold-Chiari malformation. Dev Med Child Neurol 1993;35:42-48.

14. Ruge JR, Masciopinto J, Storrs BB, Mclone DG. Anatomical progression of the Chiari II malformation. Child's Nerv Syst 1992;8:86-91. 